\title{
Self-translation as Auto-Communication: A Cultural Semiotic Approach to Self Translation
}

\section{Sachin Ketkar}

\begin{abstract}
The current paper explores the poetics and politics of ambivalent phenomenon of self-translation by the bilingual writers writing in Marathi and English in the light of semiotics of culture, a theoretical framework developed by the Tartu- Moscow School of cultural semiotics under the leadership of Yuri Lotman. The paper argues that while bilingualism and translation in broadest semiotic sense of the terms are intrinsic to any creative phenomenon and any communication according to Lotman, the Anglo-Bhasha self-translations of literary texts are distinctive historical products of the postcolonial 'semiosphere', hence caught up in the politics of identity, cultural asymmetry and cultural change. The Anglo-Bhasha bilingual writers situated on the boundary separating English and the Bhashas were critical agents in generating not only modernity but also providing 'selfdescription' of who we are culturally. They found themselves embodying this boundary within and without. In a sense, the act of self-translation is an act of what Lotman calls 'auto-communication' where though the addresser and the addressee of the communication is the same person; the act subtly transforms the personality of the subject. Self-translation as cultural phenomenon can be seen as involving not just bilingual individuals but the entire culture generating new information for itself, and restructuring its own personality. In the historical context of colonialism and its aftermath, this generation new information and restructuring of personality describes the phenomenon of modernity. As the bilingual writers were the upper caste elites generating 'self-description' of the semiosphere, this theorization may help us to understand how emergence of modernity and reformulation of identity in the nineteenth century was a
\end{abstract}


form of self- translation not just by the individuals but by the entire culture. It was by no means derivative, but a creative one involving self-discovery and self reformulation by the culture in conversation with itself. The cultural semiotics perspective would shed further light on the creative or 'incestuous' processes of cultural change and modernity.

Key words: Self-translation, postcolonialism, identity, modernity, cultural semiotics

“.....translating your own poems

Is like making love to your own daughters

It ought to be a cognizable offence

Taboo

Carry a stigma

There ought to be a law against translating your own poems

(Unless the law against incest already covers it)

Since it would be like seducing your own daughter

Arun Kolatkar (Making Love to a Poem, The Boatride and Other Poems, 2010, 222)

Arun Kolatkar's 'Making Love to a Poem' in the collection The Boatride and Other Poems (2010) agonizes over his bilingual creativity, his place in Marathi culture as a bilingual writer and his translation activity. Kolatkar was never very famous for being straightforward 'autobiographical', however this poem, put as his jotting in the appendix of the collection deals probably with the vicious attack on his bilingual creativity from the nativist and nationalist critics.

Though bilingualism and bilingual creativity are sociallinguistic facts in the multilingual Indian subcontinent since ages, the Anglo-bhasha bilingualism has a peculiar place in the cultural history of the land. This bilingualism is not just a product of contact between two languages because of geographical or cultural 
proximity, or migration, but also a product of the colonial enterprise and colonial modernity. Hence, much of the ambivalence, opposition and even admiration of this sort of bilingualism can be understood in the context of the problematic status of colonial modernity and colonial history.

Major literary figures of the nineteenth century like Bankim Chandra Chatterjee (1838-1894), Michael Madhusudan Dutt (18241873), Govardhanram Tripathi (1855-1907), Vishnushastri Chiplunkar (1850- 1882) and Rabindranath Tagore (1861-1941) were accomplished bilingual and at times even polyglots. Apart from major literary forms like the modern novel and the article, they also introduced sub-forms like the sonnet and the blank verse to the bhasha literature. Understanding of the Anglo-bhasha bilingualism is critical for our understanding of the development of Indian modernity which cannot be understood without contextualizing it within the phenomenon of colonialism and the rise of modern idea of nation.

In the past sixty years, the bilingual writers like Arun Kolatkar, Dilip Chitre, Vilas Sarang, Gauri Deshpande and Kiran Nagarkar have played a considerable role in establishing modernism in Marathi literature and in Indian writing in English. Bilingualism also seems to be related to the phenomenon of displacement and migration, which has received great deal of attention in the case of Indian English Diaspora novels, but has not been mapped adequately in the case of bhasha writers. There was a vicious attack on bilingual imagination from various quarters like nativism and nationalism, which has lead to subsequent marginalization of certain authors like Sarang and Nagarkar in Marathi literary scenario. Hence the negative perception of the Anglo-bhasha bilingualism is closely connected to the negative perception of Indian writing in English 
among many bhasha writers and critics. Even Sujit Mukherjee (1981) accused Tagore of committing 'perjury' by translating his own poems in order to please his Anglophone audience.

Vilas Sarang's essay 'Self- Translators' (1981) is a significant one as it departs from this general negative outlook towards self translation. He discusses the world renowned selftranslators like Beckett, Tagore and Nabokov. This phenomenon, according to Sarang problematizes the conventional understanding of translation. He notes that self translation is not merely imitation, but also a creation, and stands in its own right, and blurs the distinction between the original and translation. Discussing the idea that self- translator can claim far greater freedom and one can in fact adversely criticize a self- translation for not taking sufficient liberties with the source text. Sarang points out that the motives behind self- translation are more complex than the desire for fame or rewards by reaching out to larger audience. Sarang says that for a bilingual creative writer writing a poem in only one language must seem an incomplete process, and self translation often implies reassuring oneself that the poem exists. To self-translate is to reconcile 'Self' and 'Anti-Self'. He reworks the famous Descartes's quotation and says "I translate myself, therefore I exist".

The current paper explores the poetics and politics of ambivalent phenomenon of self-translation in the light of semiotics of culture, a theoretical framework developed by the Tartu- Moscow School of cultural semiotics under the leadership of Yuri Lotman. Drawing upon system thinking, information theory, chaos theory and cybernetics, Yuri Lotman in The Universe of the Mind: A Semiotic Theory of Culture (1990) complicates, and critiques the familiar atomistic model provided by Ferdinand de Saussure of how meanings are made and comes up with an alternative holistic and 
complex framework for explaining how meanings are generated.

If we look at any communicative situation, like the conversation we are having in this room and explain how meanings are made, Saussure would point out that I am using words (paroles) which you are able to understand because we share a common language (langue). Paroles or words are tangible and can be experienced, i.e. they are empirical while language is a system we have internalized and hence not tangible or empirical. Saussure took the sign as the organizing concept for linguistic structure, using it to express the conventional nature of language in the phrase "l'arbitraire du signe" terms this empirical aspect of meaningmaking as signifier or signal and the intelligible and non-tangible aspect as signified. The relation between the two is not cause-effect but arbitrary and conventional. This conventional and arbitrary relation is called 'code'. Hence in the present communicative situation, I am the addressor who encodes a message and transmit it over the channel (here, the spoken medium or written medium) and you as the addressee decode it and thus understand it. It assumes that the code involved in encoding and decoding are identical and the transmission of message is a linear and predictable process. Saussure took the sign as the organizing concept for linguistic structure, using it to express the conventional nature of language in the phrase "l'arbitraire du signe". As we are aware, this model of analysis of 'langue' in a formalistic way became the cornerstone of Saussurean structuralism which used this model for analysis of any cultural phenomenon.

Lotman critiques this model by pointing out that this model not only reflect very limited view of communication as it does not explain how new meanings are made nor how older meanings and cultural memory are stored is involved in communication. He points 
out that the code used for encoding by the addressor and the code used to decode by the addressee are hardly identical in real life and hence each communicative act is an unpredictable one involving translation. The generation of new information is made possible because of this intrinsic unpredictability and translationality in the process of communication.

The difference between the two codes arises because of personal and the cultural histories of the addressor and the addressee. He goes on to make a distinction between the code, which is artificially created convention and language which is combination of code and history. He argues that in actual life there is more than one language (semiotic systems) involved in a given communicative situation and for two non-identical languages to come together and be involved in meaning generation what is required the space that accommodates multiple languages and a mechanism for translation which may be human consciousness. Hence the mechanism for meaning generation, according to Lotman is far more complex in reality than Saussure assumed. It involves at least two non-identical languages, a translational mechanism and the space which can accommodate these things. Lotman argues that a single semiotic system cannot emerge, exist or function in isolation and has to be immersed in a semiotic space to come into being and work. Using an analogy from biosciences, Lotman terms this space 'the semiosphere'. Hence in Lotman's model, the unit of analysis is not a single langue/parole, but the semiotic space consisting of multiple semi or non identical languages forming a complex system of which other languages are both part of the larger systems as well as systems in their own right. This heterogeneous complex system of semiosphere is characterized by the existence of internal as well as external boundaries. Asymmetry, as between the core nuclear structures of the semiosphere and less structured languages on the 
boundaries, is the structural principle of the given semiosphere. Lotman in " On the Semiosphere' ( 2005) also notes, "All levels of the semiosphere, from human personality to the individual text to the global semiotic unity - are a seemingly inter-connected group of semiospheres, each of them is simultaneously both participant in the dialogue (as part of the semiosphere) and the space of dialogue (the semiosphere as a whole). Lotman also points out the principle of isomorphism inherent to the semiosphere.. This principle creates, "a distinct parallelism between individual consciousness, the text and culture as a whole."

This 'cultural semiotics' framework sees the entire cultural space or 'the semiosphere', instead of individual isolated languages, as the generator of meaning. According to this theory, translation (from one semiotic system into another- across boundaries and asymmetries) is the principal mechanism of meaning generation of a given semiosphere. As it demonstrates that the mechanism that produces the image of the past in the present by translating the texts from the past into contemporary language and simultaneously transferring it to the past is also a dialogic -translational mechanism, it becomes possible for us to see that tradition (cultural memory) and modernity (generation of new information) are not oppositional categories but mutually shaping processes generated by the dialogic mechanism of translation inherent in all cultural spaces in every period of history. These two processes are also critical to our understanding of cultural history and cultural identity.

Lotman also provides a model for analysis of the phenomenon of cultural change based on this system thinking, chaos theory and information theory. He notes that cultures and semiotic systems change in two ways: they change gradually, linearly and predictably or they change abruptly, non-linearly and unpredictably 
or in his terms 'explosively'. "Culture, whilst it is a complex whole, is created from elements which develop at different rates, so that any one of its synchronic sections reveals the simultaneous presence of these different stages. Explosions in some layers may be combined with gradual development in others. This, however, does not preclude the interdependence of these layers. Thus, for example, dynamic processes in the sphere of language and politics or of morals and fashion demonstrate the different rates at which these processes move. (2004:12)"

Utility of this framework for analysis of Indian cultural situation which is inherently multi-lingual and translational is evident. You can conceptualize Gujarati semiosphere or Marathi semiosphere as systems in their own right with internal heterogeneity, asymmetry and boundaries or parts of a greater whole - Indian Semiosphere which has its own internal heterogeneity, asymmetries and boundaries which in turn can be seen as a part of greater South Asian Semiosphere, Asian Semiosphere or the planetary semiosphere. Indian literatures can be considered as expression of the Indian 'semiosphere'. It allows us to analyze dialogic relations, dynamics of translation and texts between languages, Indian languages by viewing them not only as systems in their own right but also viewing as parts of a larger system of the Indian semiosphere, which in turn can be analyzed as being a part of a planetary semiosphere. This may explain differential developments happen in some languages fairly early (e.g. avant-garde modernism in Bengali or Dalit literature in Marathi) while in some languages they happen later.

The Marathi semiosphere developed in dynamic asymmetrical relationship between the colonizers ("them") and "us", generating new external boundaries between the colonizing culture, 
and colonized on the one hand, and new equations and patterns of internal boundaries, heterogeneities and asymmetries as well. Modernity according to the cultural semiotics model is no longer a singular code, a singular secondary modelling system that pervades or would pervade the entire cultural space. Rather it could be seen as a translational phenomenon i.e. a phenomenon produced by the semiotic mechanism of translation, generating new information or explosive changes in some layers, and in ternary structures such as India these explosive changes would hardly penetrate all the layers in the same dramatic way.

In the development of a semiosphere, Lotman notes that "The highest form and final act of a semiotic system's structural organization is when it describes itself. This is the stage when grammars are written, customs and laws codified. The stage of selfdescription is a necessary response to the threat of too much diversity within the semiosphere: the system might lose its unity and definition, and disintegrate (1990:128)". The core of the semiosphere which generates the self description of who 'we' are remained in the hands of the traditionally literate Brahmin castes. This core was built on exaltation of what Ramanujan (2004:348) following Singer and Redfield would call 'great traditions' or 'hightextual 'margiya' traditions which are pan- Indian. The language of self-definition of the anticolonial nationalist model of Indian culture is largely in terms of the Sanskritized and upper caste elite view of culture. This model was built not only upon the bilingual boundary of the colonizer, the colonized but also the internal boundaries separating the 'materialistic' activities from the 'spiritual' ones as Partha Chatterjee (2010) has noted.

However, this new asymmetry produced a new figure on the cultural scene: the English educated upper-caste bilingual 
intellectual who was simultaneously on the boundary of the colonizing culture and at the core of colonized Marathi semiosphere. This bilingual intellectual was critical agent in creation of translation culture in the nineteenth century as well as generation of modernity.It can be argued that while bilingualism and translation in broadest semiotic sense of the terms are intrinsic to any creative phenomenon and any communication according to Lotman, the Anglo-Bhasha self-translations of literary texts are distinctive historical products of the post-colonial semiosphere, hence caught up in the politics of identity, cultural asymmetry and cultural change. The Anglo-Bhasha bilingual writers situated on the boundary separating English and the Bhashas were critical agents in generating not only modernity but also providing 'self-description' of who we are culturally superior. They found themselves embodying this boundary within and without. In a sense, the act of self-translation is an act of what Lotman calls 'auto-communication'.

In his analysis of the significance and function of autocommunication, Lotman in fact continues his critique of Saussurean structuralism which he sees is based primarily on the model of " selfto -other' or ' I-You' communication in which the I is the subject of the communication, the possessor of the information, while the ' $\mathrm{s} / \mathrm{he}$ ' is the object, the addressee. In this instance it is assumed that before the act of communication there was a message known to 'me' and not known to 'him/her'.

Lotman notes, "The predominance of communications of this type in the culture we are used to overshadows the other direction in the transmission of information, a direction which we can schematically describe as the 'I-I' direction. The case of a subject transmitting a message to him/herself, i.e. to a person who knows it already, appears paradoxical. Yet it occurs quite frequently 
and has an important part to play in the general system of culture....But how does this odd situation come about whereby a message transmitted through the 'I-I' system is not wholly redundant and even acquires some new supplementary information (1990:21).

Lotman goes on to argue, "The 'I-s/he' system allows one merely to transmit a constant quantity of information, whereas the 'I-I' system qualitatively transforms the information, and this leads to a restructuring of the actual I itself. In the first system the addresser transmits a message to another person, the addressee, but remains the same in the course of the act. In the second system, while communicating with him/herself, the addresser inwardly reconstructs his/her essence, since the essence of a personality may be thought of as an individual set of socially significant codes, and this set changes during the act of communication (1990:22)".

Lotman notes, "Human communication can be constructed along two models. In the first instance we are dealing with already given information which is transmitted from one person to another with a code which remains constant for the duration of the act of communication. In the second instance we are dealing with an increase in information, its transformation, and reformulation and with the introduction not of new messages but of new codes, and in this case the addresser and addressee are contained in the same person. In the process of this autocommunication the actual person is reformed and this process is connected with a very wide range of cultural functions, ranging from the sense of individual existence which in some types of culture is essential, to self-discovery and auto-psychotherapy (1990:29)".

Auto-communication, in short, plays a significant role in reconstruction of essence of self and cultural identity. If self- 
translation by the Anglo-bhasha writers is seen as an instance of auto-communication wherein the authors transmit the message which they already know, to themselves in another language, we can explain how they are in fact creating new information which is often unpredictable to themselves. At the same time they are 'restructuring the essence of their personalities, their 'I'. Self-translation thus, become a creative mode of negotiating with the self divided by the boundaries of English and Bhashas within and without for the bilingual writer. It is simultaneously an act of quest for self identity and act of self-fashioning in the colonial and postcolonial semiosphere. Besides, as this upper-caste Anglo-Bhasha bilinguals also occupied the core of Marathi semiosphere by generating 'selfdescription' for Marathi culture, this self restructuring through self translation can be seen as playing a vital role in modernizing Marathi literary language, Marathi culture and indigenizing English in India.

Lotman goes on to argue that culture itself can be treated both as the sum of the messages circulated by various addressers (for each of them the addressee is 'another','s/he'), and as one message transmitted by the collective 'I' of humanity to itself. From this point of view human culture is a vast example of autocommunication. Basing his theory of culture on his semiotically bilingual model of communication, Lotman says, 'for culture to exist as a mechanism organizing the collective personality with a common memory and a collective consciousness, there must be present a pair of semiotic systems with the consequent possibility of text translation. The 'Is/he' and 'I-I' communicative systems form just such a pair' (1990: 33-34).

If culture is visualized as autocommunication involving translation between 'I- s/he' system and 'I-I' systems of 
communication, we can understand self-translation as a larger cultural phenomenon encompassing the entire culture. Besides, these individual acts of self-translations can also be seen as reflecting the principle of 'isomorphism' intrinsic to the semiosphere which creates "a distinct parallelism between individual consciousness, the text and culture as a whole." Thus, individual acts of selftranslations, self- translated texts and the culture, in this case, the Marathi culture, can be seen as isomorphic.

Thus self-translation as cultural phenomenon can be seen as involving not just bilingual individuals but the entire culture generating new information for itself, and restructuring its own personality. In the historical context of colonialism and its aftermath, this generation new information and restructuring of personality describes the phenomenon of modernity. As the bilingual writers were the upper caste elites generating 'self-description' of the semiosphere, this theorization may help us to understand how emergence of modernity and reformulation of identity in the nineteenth century was a form of self- translation not just by the individuals but by the entire culture. It was by no means derivative, but a creative one involving self-discovery and self reformulation by the culture in conversation with itself. The cultural semiotics perspective would shed further light on the creative or 'incestuous' processes of cultural change and modernity. In this light, Sarang's proposition, "I translate myself, therefore I exist" may be read as the utterance of the entire Marathi culture.

\section{REFERENCES}

Chatterjee, Partha. 2010. Empire and Nation: Selected Essays. New York: Columbia University Press.

Kolatkar, Arun. 2010. The Boatride and Other Poems, Mumbai: Pras Prakashan, 222-237. 
Lotman, Juri. 2005. 'On the semiosphere." Translated by Wilma Clark.. Sign Systems Studies 33.1, Web

--- 2004. Culture and Explosion. Edited by Marina Grishakova. Translated by Wilma Clark. Mouton de Gruyter. Berlin • New York.

--- 1990. Universe of the Mind. A Semiotic Theory of Culture. Bloomington/Indianapolis: Indiana University Press.

Mukherjee, Sujit. 1981. Translation as Discovery and other essays on Indian Literature in English Translation. New Delhi: Allied

Ramanujan, A.K. 2004. The Collected Essays of AK Ramanujan. Edited by Vinay Dharwadkar. Oxford University Press.

Sarang, Vilas. 1981. "Self- Translators", Journal of South Asian Literature, Vol. 16, No.2. Miscellany, Asian Studies Center, Michigan State University, Summer, Fall, Pp 33-39. Web 